\title{
|||||||||||||||||||||||||||||||||||||||||||||||||||||||||||||||||.
}

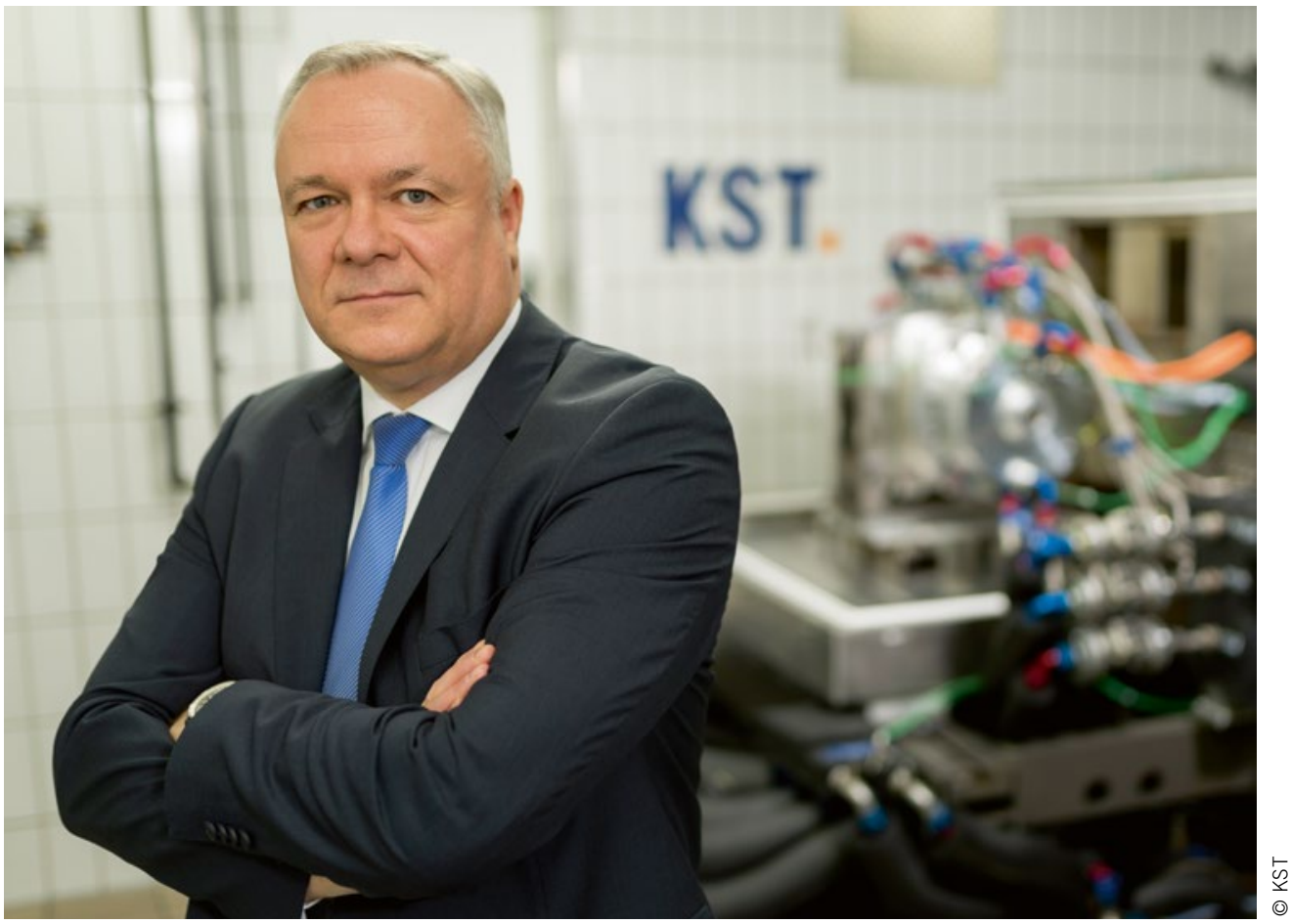

Prof. Dr. Gerhard Reiff

Vorsitzender der Geschäftsführung, KST-Motorenversuch GmbH \& Co. KG

\section{Marktveränderung für Prüfdienstleister}

Wer entscheidet letztendlich über das Ende des Verbrennungsmotors in der individuellen Mobilität - der Kunde voller Begeisterung für die ansatzlose und überwältigende Beschleunigung des E-Motors oder die etablierte Industrie, die mit den installierten Kapazitäten solange wie irgend möglich Profit machen möchte? Und nicht zu vergessen die Öl- und Gasindustrie, die ohne Otto- und Dieselmotoren bestimmte Destillate ihrer Raffinerien nicht mehr in ausreichender Menge an den Kunden bringt. Oder ist der nachwachsenden Generation die Antriebsart völlig egal - Hauptsache vollumfänglich vernetzt sein und dabei möglichst autonom gefahren von A nach B kommen?

Ein traditionsreiches Motorentesthaus wie KST muss mit all diesen unsicheren Zukunftsszenarien umgehen lernen. In den ersten Jahrzehnten der nun fast 50-jährigen Unternehmensgeschichte war es noch relativ einfach, der Nachfrage des Markts gerecht zu werden. Die Motoren wurden größer oder auch kleiner, aber immer effizienter, und im Abgas- wie Antriebsstrang komplexer. Jedoch blieb das Automobil eben immer traditionell mit Benzin oder Diesel befeuert.

Dann, in der letzten Dekade, wurde unübersehbar, dass die Komplexität zunehmen wird. Auch bei KST haben sich die Investitionsschwerpunkte in Richtung E-Motoren und komplexe Antriebsstränge verschoben. Nun müssen wir uns auf die Zukunft vorbereiten. Dort ist noch nicht abzusehen, ob die Brennstoffzelle der Favorit ist oder eine verbesserte Batterie diese überflüssig macht - zumindest im Pkw. Der ökonomische und ökologische Nutzen des Hybridantriebs wirft aufgrund des Primärressourcenverbrauchs auch hier zumindest noch zusätzliche nicht beantwortete Fragen auf.

Allen Trends zu folgen und sich mit einem jeweiligen signifikanten Testportfolio darauf vorzubereiten, kann sich ein mittelständisches Unternehmen kaum leisten. Denn ein einziger strategischer Fehlgriff wird empfindliche Auswirkungen haben. Das betrifft nicht nur die rein monetären Gesichtspunkte, sondern auch wesentlich die essenziell wichtigen personellen Ressourcen. Den Anforderungen aller Entwicklungen gerecht zu werden, die sich bei einem Dienstleister kumulieren, bedarf einer wohl überlegten Personalstrategie und -entwicklung.

Aber gibt es nicht auch spezielle Chancen aus diesem spannenden Geschehen für einen Prüfdienstleister? Die Antwort muss klar „ja“ sein. Denn schon aktuell ist eine deutliche Verschiebung des Entwicklungsrisikos für neue Antriebstechnik vom OEM in Richtung Tier-1-Lieferant zu erkennen. Und dieser wiederum scheut oftmals die nicht unerheblichen Investitionen in neue Testkompetenzen. Wer sich als Dienstleister in dieser sich verändernden Wertschöpfungskette mit dem richtigen Gespür für die Kernkompetenzen von morgen und übermorgen positioniert, wird in den nächsten Jahrzehnten ein Stück weit aus dem Durchschnitt herausragen und mit zur weiteren Veränderung unserer Industrie positiv beitragen. 